\title{
Economic and Environmental Consequences of Market Power in the South-East Europe Regional Electricity Market
}

\author{
Verena Višković*, Yihsu Chen ${ }^{* *}$, Afzal S. Siddiqui***, and Makoto Tanaka****
}

\begin{abstract}
Amstract
Market power in electricity and emission-permit markets in the South-East Europe Regional Electricity Market, which comprises both EU members subject to the EU Emissions Trading System (ETS) and non-EU members exempt from it, affects social welfare and carbon leakage. We examine its impact under three market settings: perfect competition (PC) and two leader-follower versions, in which a leader can exert market power in either the electricity market (S-T) or both the electricity and permit markets (S). Under PC, carbon leakage is equal to $11 \%-39 \%$ of ETS emission reduction depending on the cap stringency. Generally, in S-T, the leader's capacity withholding results in ETS emissions below and non-ETS emissions above PC levels. However, carbon leakage is lower vis-à-vis PC as the ETS emission reduction offsets the non-ETS emission increase. Finally, in S, the leader's propensity to lower the permit price increases ETS emissions and exacerbates carbon leakage compared to S-T.
\end{abstract}

Keywords: Bi-level model, Carbon leakage, EU ETS, Energy Community, Market power

http://www.example.com

\section{Introduction}

Two major historic processes of the last four decades have shaped current electricity markets worldwide. First, the deregulation of the electricity industry, which in some cases resulted in electricity markets characterised by oligopolistic ownership structures (Wilson, 2002) potentially subject to the exercise of market power. Electricity markets are particularly vulnerable to the manipulation of prices above competitive levels due to relatively inelastic short-term demand and lack of storage (Borenstein, 2000). Furthermore, market separation due to network congestion can play an important role in the extent to which market power can be exercised (Neuhoff et al., 2005).

Second, concerns about the effects of greenhouse gases (GHGs) on climate change led to carbon pricing through transferable property rights, e.g., allowances or permits. Emission permits are commonly traded under cap-and-trade (C\&T) systems, which can also be subject to market power. For example, Hahn (1984) shows that any initial allocation of permits to a participant with market power that deviates from the quantity of permits consumed in equilibrium results in market inefficiencies, i.e., a participant with market power will either raise the permit price above or push it below the perfectly competitive level.

\footnotetext{
${ }^{*}$ Department of Statistical Science, University College London.

** Department of Electrical and Computer Engineering, University of California, Santa Cruz.

${ }^{* * *}$ Corresponding author. Department of Statistical Science, University College London, Department of Computer and Systems Sciences, Stockholm University, and Department of Decision Sciences, HEC Montréal. Send correspondence to Department of Statistical Science, University College London, Gower Street, London WC1E 6BT, United Kingdom. E-mail: afzal.siddiqui@ucl.ac.uk

${ }^{* * * *}$ National Graduate Institute for Policy Studies (GRIPS) and Research Institute of Economy, Trade and Industry (RIETI), Japan.
} 
The exercise of market power in a single market has attracted attention in the literature; however, the interaction of product and permit markets both subject to market power has been less investigated. Kolstad and Wolak (2003) examine the circumstances in the California electricity market in 2000 and 2001 where part of the market (Los Angeles area) was subject to the $\mathrm{NO}_{x} \mathrm{C} \& \mathrm{~T}$. They find evidence that prospects for exercising market power in the electricity market might have been enhanced via the C\&T. Specifically, firms that owned plants both in the area subject to the C\&T and outside of it might have intentionally paid higher permit prices. Due to the higher permit price, they were able to justify higher offers into the electricity market despite not using the more-polluting plants in a way consistent with the higher marginal cost of production given by the higher permit price. In this way, they could have earned higher profits on less-polluting plants and/or uncapped plants.

Besides price manipulation, regional electricity markets where only a subregion of the market is subject to a C\&T, such as the Pennsylvania-New Jersey-Maryland (PJM) Interconnection, California, and South-East Europe, are at risk of carbon leakage (Burtraw et al., 2006, Višković et al., 2017), i.e., an increase in emissions in an uncapped subregion of a regional market as a result of introducing a binding cap in the subregion subject to a C\&T. A binding cap results in a positive permit price, which translates into higher electricity prices in the capped subregion and entices the uncapped subregion's production leading to an increase in emissions in the uncapped region. Since exercise of market power raises prices above perfectly competitive levels, the issue is whether the exercise of market power by a firm located in the capped subregion of a regional market can exacerbate carbon leakage through its simultaneous manipulation of the permit price. In particular, given the prominent role of C\&T markets in curbing $\mathrm{CO}_{2}$ emissions, it is crucially important to examine their vulnerability to such strategic behaviour. Towards that end, we investigate the impacts of (i) environmental regulation under perfect competition, (ii) market power in electricity markets only, and (iii) market power in both electricity and permit markets.

We address these issues via a stylised 22-node network of the South-East Europe Regional Electricity Market (SEE-REM) that spans EU and non-EU countries in which EU members are covered by the EU Emissions Trading System (ETS) and non-EU countries are exempt from it (Figure 11. We choose a single firm with fixed capacity in the ETS part of the market as the dominant firm. In order to investigate the short-term impact of market power in both electricity and permit markets, we analyse three market settings. First, all firms are price takers in both electricity and permit markets under perfect competition. Second, a leader-follower setting provides the leader with market power in the electricity market only, whereas all other firms are price takers, and the C\&T is modelled through an exogenous permit price, i.e., a carbon tax. Such a setting enables us to assess the impact of market power in the electricity market only under varying levels of $\mathrm{CO}_{2}$ emission restrictions. Finally, a leader-follower setting provides the leader with market power in both electricity and permit markets, whereas all other firms are price takers, and the C\&T is modelled through an ETS emission constraint. Via this framework, we analyse the impact of market power on prices, output, consumption, flows, emissions, and social welfare.

We find that under perfect competition, a binding cap on ETS emissions curbs ETS production. As the cap tightens, the price differential between ETS and non-ETS areas of the market increases, thereby enticing non-ETS production and leading to higher non-ETS emissions. Consequently, there is carbon leakage between 39\%-11\% for caps of 10\%-40\% reduction, respectively, compared to the baseline (Višković et al. 2017). If the leader can exert market power in the electricity market only, then its strategy depends on the marginal technology, which changes with the stringency of the environmental regulation. When natural gas is the marginal technology, which occurs at lower carbon-tax levels, the leader's strategy is to withhold production from its dominant technology (coal) in order to raise electricity prices and reap higher profits on its operating power plants. Higher electricity prices entice ETS natural-gas (including the leader's) and non-ETS production, which partly replaces the share vacated by the leader's coal plants. As a result, ETS (non-ETS) emissions fall below (rise above) the perfectly competitive levels. Since the reduction in ETS emissions offsets the 
Figure 1: SEE-REM nodal representation

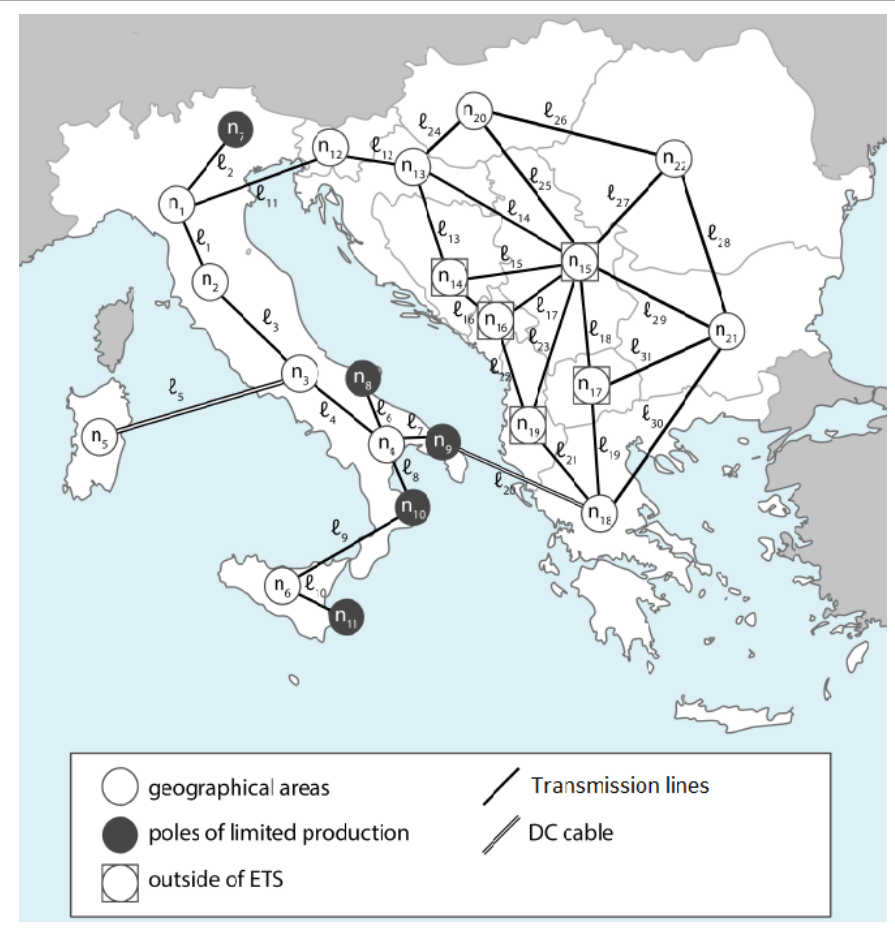

increase in non-ETS emissions, carbon leakage is lower compared to the perfectly competitive setting. For a carbon tax such that coal reaches cost parity with natural gas, the leader adopts an opposite strategy coal-wise. In particular, it expands coal production in order to set equilibrium prices. Higher electricity prices entice ETS coal and non-ETS production resulting in ETS and non-ETS emissions as well as carbon leakage above the perfectly competitive level. With the additional possibility to influence the permit price, the leader holds back more coal compared to the carbon-tax setting. A lower abatement cost results in higher ETS natural-gas production and ETS emissions compared to the carbon-tax setting leading to higher carbon leakage. When coal reaches marginal-cost parity with natural gas, the leader expands coal to a lesser extent compared to the carbon-tax setting as it does not want to increase the permit price. Contrary to the carbon-tax setting, since the fringe firms in the ETS cannot increase coal production because of the cap, they increase natural-gas production. This leads to lower ETS emissions and carbon leakage compared to the carbon-tax setting. Generally, the leader is able to reap higher profits when it has the ability to manipulate both markets, except in the case of a tighter cap when its expansion of coal production is limited by the effect that it might have on the permit price.

The remainder of this paper is structured as follows. In Section 2, we review the relevant literature and explain our paper's contribution. Section 3 describes the mathematical models used and explains how the data are implemented, whereas in Section 4, we analyse and discuss the results. Finally, Section 5 summarises our work and provides directions for future research. Appendices A B and C contain the calibration, additional results, and the mathematical reformulation, respectively. They are available online as Supplementary Materials on the Energy Journal website.

\section{Literature Review}

Market power in electricity markets remains a concern (Tangerås and Mauritzen, 2018) and is commonly examined through market settings such as Cournot oligopoly, dominant firm-competitive 
fringe, and multiple dominant firms with a competitive fringe. For example, Gabriel and Leuthold (2010) use a bi-level model to study the impact of market power by a single dominant firm in an electricity market. They find that the dominant producer is able to raise electricity prices above perfectly competitive levels by holding back capacity with the extent of the withholding bounded by the cheapest plant of the follower firms. Meanwhile, Sauma and Oren (2007) devise a tri-level model with a regulated planner deciding upon transmission expansion at the uppermost level, power companies making generation-capacity investment decisions at the middle level, and market clearing at the lowest level. They implement this framework in a Chilean case study to demonstrate the complexities of attaining politically feasible transmission plans when generators exert market power.

Market power in an electricity market can indirectly affect even a perfectly competitive permit market. Limpaitoon et al. (2011) develop an equilibrium model of an oligopolistic electricity market with a C\&T where firms are price takers to study the impact of market structure on market outcomes. Although it is generally expected that more competitive markets have higher permit prices, Limpaitoon et al. (2011) find that this might not be the case when the ownership of relatively cleaner power plants is concentrated among fewer firms. In particular, if cleaner firms withhold generation in order to raise electricity prices, then dirtier firms increase production to compensate partly for the share vacated by the cleaner ones. This leads to a higher consumption of permits, thereby driving up the permit price. The impact of permit allocation and Cournot behaviour on electricity prices is investigated by Lise et al. (2010) in the EU ETS context. They show higher electricity prices for consumers and windfall profits for producers result from ETS permits.

Firms with market power in the product market could also have market power in the permit market and, thus, directly manipulate the permit price in their favour. Sartzetakis (1997) models a product market as a Cournot duopoly where one of the firms is a Stackelberg leader in the permit market. He concludes that a leader can intentionally raise the permit price as part of its strategy to raise competitors' costs (Salop and Scheffman, 1983) and that its ability to do so depends on its pre-regulation market share, regulation stringency, and the competitiveness of the product market. In the context of electricity markets with a secondary C\&T, i.e., where firms trade permits among themselves, Chen and Hobbs (2005) find that the permit price is a function of both the share of a firm's capacity in the electricity market and the direction and magnitude of its net position in a C\&T. More specifically, if a leader is a net seller in the permit market, then holding back permits is profitable as it results in a higher permit price, which means that the leader can reap higher profits from the sale of permits (Chen et al. 2006). However, this strategy may not be profitable when a leader is a net buyer of permits, in which case it could be profitable for the leader to resort to a monopsonistic strategy in order to lower the permit price. Chen et al. (2018) similarly demonstrate the impact of market power in the context of the U.S. Clean Power Plan when comparing mass- and performance-based emission policies.

Besides welfare effects, manipulation of electricity and permit prices can also affect carbon leakage as electricity imports increase from regions without environmental regulation. Emission leakage can be considerable depending on the sector and can further increase if the decline in fossil-fuel prices resulting from lower consumption in regulated regions entices non-regulated regions' consumption, thereby increasing the emission intensity of the non-regulated regions' production (Fischer and Fox, 2012). Output-based allocation seems to be more efficient at mitigating leakage compared to other forms of allocation such as grandfathering or auctions (Jensen and Rasmussen, 2000, Bushnell and Chen, 2012). Low availability of hydropower can push up electricity prices in the regulated region, which could incentivise firms in the uncapped region to export, thereby increasing leakage (Višković et al., 2017).

Interaction between market power and carbon leakage in the short term has been examined by Fowlie (2009) in the context of the California spot and forward electricity markets. Imperfectly competitive market conditions are reflected in firms that are asymmetric Cournot oligopolists. Firms are price takers in the permit market facing a permit price of $\$ 25 / \mathrm{t}$, which reflects their inability to 
manipulate the permit price as the permit price is determined by a much larger C\&T. Fowlie (2009) shows that not only strategic behaviour in an electricity market subject to unilateral carbon-reduction policy reduces emission leakage compared to perfect competition but also the less competitive the product markets, the lower the leakage.

In the same spirit as Fowlie (2009), we examine the interaction of market power and leakage in the short run. Unlike the Cournot model in Fowlie (2009), we assume that the leader anticipates its competitors' response to its decisions as a Stackelberg leader. In addition, we allow for market power in the permit market. In fact, our model of the coupled electricity and permit markets is similar to Chen et al. (2006); however, different from them, we model the first-stage C\&T, i.e., initial allocation of permits rather than the second stage where firms trade permits among themselves.

To complement the preceding literature, we analyse how market power exercised by a single dominant firm located in the regulated subregion of a regional market affects social welfare and carbon leakage under varying environmental regulation stringency. Our aim is to answer the following research questions:

1. What is the impact of environmental regulation under perfect competition?

2. What is the incremental impact of market power in electricity markets only?

3. What is the incremental impact of market power in both electricity and permit markets?

\section{Research Methodology}

\subsection{Model Structural Assumptions}

We consider a short-term, i.e., fixed capacity, multi-period auction-based electricity market with one strategic firm and an independent system operator (ISO) whose problem embeds follower firms. Firms are denoted by $i$, which is partitioned into $s$ and $j$, referring to the leader and the follower firms, respectively. Firms own generating units, $u$, at different nodes, $n$. At each time period, $t$, firms are dispatched by the ISO with the objective of maximising total net surplus in the market, thereby, in the presence of transmission-constrained networks, determining locational marginal prices (LMPs), $\lambda_{t, n}$ (Hogan, 1992, Schweppe et al., 1988). Firms can sell power at the nodes where they own capacity. The ISO transports power from firms to consumers, i.e., purchasing power from nodes with excess supply and selling it to nodes with excess demand. Therefore, the ISO is both an auctioneer and an arbitrageur. The arbitrage is necessary to eliminate any non-cost-based price differences that might occur in the system (Hobbs 2001). We model demand net of variable renewable production, i.e., solar and wind, with a point elasticity. The transmission network is divided into AC and DC parts. We assume that in the AC network, power flows according to Kirchhoff's voltage and current laws approximated using the DC load-flow model (Schweppe et al., 1988). Since flows on DC lines are treated as controllable, they are exempt from Kirchhoff's laws (Bjørndal et al. 2014). See Appendix C.1 for the nomenclature.

We take an equilibrium approach because our research questions address strategic behaviour. Some advantages of this framework are its capability to represent firm behaviour (such as exertion of market power in both primary and secondary markets), consumer behaviour (such as demand response), and physical attributes of the network (such as Kirchhoff's laws). The framework is not without its disadvantages, however, such as heavy data requirements, computational complexity of problem instances, and simplified representation of variation in hydro and other renewable production.

Copyright (C) 2018 by the IAEE. All rights reserved. 


\subsection{Mathematical Formulation}

\subsubsection{Lower-Level Problem with Welfare-Maximising ISO}

At the lower level, we have the ISO, whose quadratic programming (QP) problem is given by (1)-(9), and problem instances may be readily tackled by commercial solvers. Data for the problem instances are described in Section 3.3 and Appendix A The ISO's objective (1) is to maximise social welfare 1 by deciding quantities demanded by consumers, $d_{t, n}$, quantities generated by follower firms, $x_{t, n, j, u}$, flows, $f_{t, \ell}$, and voltage angles, $v_{t, n}$. Here, the social welfare may be calculated as the difference between the gross consumer surplus and the total generation cost, where the former is the area under the inverse demand, $D_{t, n}^{i n t}-D_{t, n}^{s l p} d_{t, n}$, summed over all time periods and nodes (Gabriel and Leuthold, 2010, Sauma and Oren, 2007). The objective function is subject to linear constraints (2)-(9). The firms' generation is limited by installed capacities, $X_{n, j, u}$, in (2). Likewise, power flows are restricted by transmission capacities, $K_{t, \ell}$, in positive and negative directions (3) and (4), respectively. Furthermore, flows on AC lines, $f_{t, \ell} \ell_{C} \in \mathcal{L}^{A C}$, are linearised using the DC load-flow approximation in (5). (6) represents the swing bus, where at an arbitrarily chosen node, the voltage angle is set to zero through the binary parameter, $S_{n^{A C}}$. (7)-(9) are market-clearing conditions. (7) imposes the condition of zero net imports, $-\sum_{n} \sum_{\ell} A_{\ell, n} f_{t, \ell}$, across all nodes, which derives from arbitrage and ensures equilibrium. (8) guarantees that the difference between quantities demanded and produced at each node equals net imports at that node, i.e., the mass-balance equation that clears the electricity market. Finally, (9) is the ETS market-clearing constraint and states that emissions produced by generating units located at nodes within the ETS (given by the product of generated quantities, $x_{t, n, i, u}$, and emission intensities of the respective units, $E_{n, i, u}$ ) must be less or equal to the emission cap, $Z$, exogenous to the ISO's problem. Dual variables are given after the colons and represent shadow prices on the associated constraints. For example, the shadow price for the binding ETS constraint 99 is the $\mathrm{CO}_{2}$ permit price, $\rho$.

$$
\begin{array}{cl}
\max _{\substack{d_{t, n} \geq 0, x_{t, n, j, u} \geq 0, f_{t, \ell}, t_{t, n} \\
\text { s.t. }}} & \sum_{t} N_{t}\left[\sum_{n}\left(D_{t, n}^{i n t} d_{t, n}-\frac{1}{2} D_{t, n}^{s l p} d_{t, n}^{2}-\sum_{j} \sum_{u \in \mathcal{U}_{n, j}} C_{n, j, u} x_{t, n, j, u}\right)\right] \\
& N_{t}\left(x_{t, n, j, u}-X_{n, j, u}\right) \leq 0: \beta_{t, n, j, u}, \forall t, n, j, u \in \mathcal{U}_{n, j} \\
& N_{t}\left(-f_{t, \ell}-K_{t, \ell}\right) \leq 0: \mu_{t, \ell}^{-}, \forall t, \ell, \\
& N_{t}\left(f_{t, \ell}-K_{t, \ell}\right) \leq 0: \mu_{t, \ell}^{+}, \forall t, \ell \\
& \left.N_{t}\left(f_{t, \ell} \ell^{A C}-\sum_{n^{A C} \in \mathcal{N}^{A C}} H_{\ell A C}, n^{A C} v_{t, n^{A C}}\right)=0: \gamma_{t, \ell}\right), \forall t, \ell^{A C} \in \mathcal{L}^{A C} \\
& N_{t}\left(S_{n^{A C}} v_{t, n^{A C}}\right)=0: \eta_{t, n^{A C}}, \forall t, n^{A C} \in \mathcal{N}^{A C} \\
& -N_{t} \sum_{n} \sum_{\ell} A_{\ell, n} f_{t, \ell}=0: \delta_{t}, \forall t \\
& N_{t}\left(d_{t, n}-\sum_{i} \sum_{u \in \mathcal{U}_{n, i}} x_{t, n, i, u}+\sum_{\ell} A_{\ell, n} f_{t, \ell}\right)=0: \lambda_{t, n}, \forall t, n \\
& -Z+\sum_{t} \sum_{n \in \mathcal{N}^{E T S}} \sum_{i} \sum_{u \in \mathcal{U}_{n, i}} N_{t} E_{n, i, u} x_{t, n, i, u} \leq 0: \rho
\end{array}
$$

\subsubsection{Optimisation Problem Constrained by an Optimisation Problem (OPcOP)}

At the upper level, we have one strategic firm, indexed by $s$, who acts as a Stackelberg leader (Hobbs et al. 2000, Gabriel and Leuthold, 2010) anticipating the followers' response to its production,

\footnotetext{
${ }^{1}$ We exclude the cost of damage from emissions here since the ISO complies with an exogenous carbon cap.
} 
$x_{t, n, s, u}$. This leader's objective is to maximise its profit, which is the difference between the revenues from electricity sales, $\lambda_{t, n} x_{t, n, s, u}$, and the costs of generation and emissions, $C_{n, s, u} x_{t, n, s, u}$, and $\rho E_{n, s, u} x_{t, n, s, u}$, respectively. The leader's objective function is subject to its generation capacities, $X_{n, s, u},[11$, and the ISO's optimisation problem (1)-(9).

$$
\begin{array}{cl}
\max _{x_{t, n, s, u} \geq 0} & \sum_{t} N_{t}\left(\sum_{n} \sum_{u \in \mathcal{U}_{n, s}}\left(\lambda_{t, n}-C_{n, s, u}\right) x_{t, n, s, u}-\sum_{n \in \mathcal{N}^{E T S}} \sum_{u \in \mathcal{U}_{n, s}} \rho E_{n, s, u} x_{t, n, s, u}\right) \\
\text { s.t. } & N_{t}\left(x_{t, n, s, u}-X_{n, s, u}\right) \leq 0: \beta_{t, n, s, u}, \forall t, n, u \in \mathcal{U}_{n, s} \\
& \text { (1) }-9
\end{array}
$$

\subsubsection{Mathematical Program with Equilibrium Constraints (MPEC)}

The OPcOP in Section 3.2.2 can be expressed as an MPEC by writing the lower level in terms of its Karush-Kuhn-Tucker (KKT) conditions given by (C-1a)-C-12 in Appendix C.2 Note that the primal and dual variables of the lower level are upper-level decision variables.

$$
\begin{array}{ll}
\max _{\Gamma \cup \Xi \cup \Psi} & \sum_{t} N_{t}\left(\sum_{n} \sum_{u \in \mathcal{U}_{n, s}}\left(\lambda_{t, n}-C_{n, s, u}\right) x_{t, n, s, u}-\sum_{n \in \mathcal{N}^{E T S}} \sum_{u \in \mathcal{U}_{n, s}} \rho E_{n, s, u} x_{t, n, s, u}\right) \\
\text { s.t. } & 11, \mathrm{C}-1 \mathrm{a}-\mathrm{C}-12
\end{array}
$$

where $\Gamma$ is the set of upper-level decision variables, $\Xi$ is the set of lower-level primal variables, and $\Psi$ is the set of lower-level dual variables, i.e., $\Gamma=\left\{x_{t, n, s, u} \geq 0\right\}, \Xi=\left\{x_{t, n, j, u} \geq 0, d_{t, n} \geq 0, v_{t, n^{A C}}, f_{t, \ell}\right\}$, and $\Psi=\left\{\beta_{t, n, j, u} \geq 0, \gamma_{t, \ell}{ }^{A C}, \delta_{t}, \eta_{t, n^{A C}}, \lambda_{t, n}, \mu_{t, \ell}^{-} \geq 0, \mu_{t, \ell}^{+} \geq 0, \rho \geq 0\right\}$.

For larger problem instances, it is not always possible to implement an MPEC directly due to its highly non-convex nature. However, an MPEC can be transformed into a mixed-integer quadratic programming problem (MIQP) through the replacement of complementarity conditions with disjunctive constraints (Fortuny-Amat and McCarl, 1981) and reformulation of the bilinear terms in the leader's objective function via strong duality from the lower level (Dorn, 1960. Huppmann and Egerer, 2015). Transformation of the MPEC into an MIQP is described in Appendix C.3

\subsubsection{Leader-Follower with Carbon Tax}

The leader-follower market setting with a carbon tax differs from the leader-follower setting with an ETS constraint in two ways. First, in the leader's objective function (10), the permit price, $\rho$, is replaced with an exogenous carbon tax, $R$. Second, in the lower-level problem, we no longer have the ETS constraint (9), but we subtract the term $\sum_{t} N_{t}\left(\sum_{n \in \mathcal{N}^{E T S}} \sum_{j} \sum_{u} R E_{n, j, u} x_{t, n, j, u}\right)$ from the ISO's objective function (1). The model is then transformed into an MIQP using strong duality from the lower-level problem.

\subsection{Data Implementation}

Here, we describe the data implementation of our numerical example, whereas the calibration to actual data is shown in Appendix A We model the full year of 2013 via 48 time blocks, i.e., four per month, weighted as in Višković et al. (2017), cf. Appendix A The numerical example for SEE-REM is the same as in Višković et al. (2017) with three exceptions. First, we take into account the ownership of power plants given the market structure especially in Italy (Iovino and Tsitsianis, 2020), and, in addition to installed capacity per node aggregated by type of technology, we explicitly model the Italian firm, Enel, which is the leader in our model 2 Second, we model hydropower production.

\footnotetext{
${ }^{2}$ From Table A-1 Enel (firm $i_{4}$ ) owns $23 \%$ of the capacity in Italy (nodes $n_{1}-n_{11}$ ). Since this is twice as much as that owned by the next-largest firm in Italy, A2A (firm $i_{1}$ ), it is reasonable to cast Enel as the leader. If another firm, such as A2A,
} 
Third, we use availability factors to account for plant outages and revisions. Nodal representation of SEE-REM together with transmission-line data (transmission capacity, resistance, and reactance), technology characteristics (marginal cost of generation and emission rates), calculation of demand net of variable renewable output with a point elasticity of -0.25 (Dietrich et al. 2005; Egerer et al., 2014, Weigt, 2006), and adjusted actual electricity prices remain the same as in Višković et al. (2017).

The nodes are selected from non-EU countries in the Western Balkans belonging to the Energy Community and their neighbouring EU member states defined as follows: Albania (AL$\left.n_{19}\right)$, Bosnia and Herzegovina (BH- $\left.n_{14}\right)$, Bulgaria $\left(\mathrm{BG}-n_{21}\right)$, Croatia $\left(\mathrm{HR}-n_{13}\right)$, Republic of North Macedonia (MK- $\left.n_{17}\right)$, Greece (GR- $\left.n_{18}\right)$, Hungary (HU- $\left.n_{20}\right)$, Italy (IT- $\left(n_{1}-n_{11}\right)$ ), United Nations Interim Administration Mission in Kosovo (XK- $\left.n_{15}\right)$, Montenegro $\left(\mathrm{ME}-n_{16}\right)$, Republic of Serbia (RS- $n_{15}$ ), Romania (RO- $n_{22}$ ), and Slovenia (SI- $n_{12}$ ). These nodes match the current configuration of European bidding zones, which should be specified in a way to reflect network congestion patterns as given on page 9 of ENTSO-E (2018) ${ }^{3}$ Tables A-2 and A-3 in Appendix A provide details about transmission lines connecting these nodes.

We explicitly model Enel through its installed capacities (based on estimates of installed capacities for 2013 collected from the firm's Website). The remaining installed capacities are assigned to 21 other actual firm $s^{4}$ and one fringe such that the aggregate installed capacities per country match those from ENTSO-E (2013) (see Table A-1 in Appendix A). When a power plant is owned by two or more firms, its capacity is split between firms proportionally to the ownership. We classify firms' installed capacities into eight technologies, viz., coal, lignite, natural gas-simple cycle, natural gas-steam turbine, fuel oil, nuclear, hydro, and mixed fuels, with operating costs and emission rates as given in Table 1

Hydropower production is modelled using hydropower availabilities rather than installed capacities of hydropower plants. In this way, any constraints related to water flows or reservoir values are already taken into account. Hydropower availabilities per firm are obtained 5 by dividing annual hydropower production by the number of hours in a year and using firms' share of hydropower production. Thus, modelled hydropower production matches actual hydropower production (ENTSOE. 2013) exactly under perfect competition (Figures A-1a and A-1b). Hydropower is included in the model at a marginal cost of $€ 0 / \mathrm{MWh}$. Non-hydro renewable production, such as solar and wind power with relatively low short-run marginal costs compared to conventional energy sources (Bushnell and Chen, 2012), is netted out from demand because it is non-controllable and is simply fed into the grid.

We multiply availability factors by net installed capacities to account for plant outages in order to obtain the available (or, derated) capacity (Bushnell et al. 2008). Since the unavailability of power plants can vary throughout the year depending on various conditions (ENTSO-E, 2013), the values that we use in Table 1 represent annual average availability.

were the leader, then the nature of the findings would depend on its portfolio and geographical dispersion. However, due to its lower installed capacity, A2A's leverage on either the electricity or the permit market would typically be less in magnitude than that exerted by Enel. A similar approach was used in Chen et al. (2006).

${ }^{3}$ In order to reflect real-world considerations, we have made three adjustments. First, Italy is modelled by 11 nodes, which correspond to its pricing zones following the rationale of Green (2007) in modelling the British power system. By contrast, ENTSO-E (2018) indicates only six zones for Italy but mentions "virtual bidding zones are not represented on the map [for Italy]," which necessitates our inserting the five additional nodes for Italy. Second, we represent Serbia and Kosovo by a single node due to lack of data availability. Third, ENTSO-E] 2018) seems to allocate Croatia and Slovenia as a single zone, whereas for purpose of comparison with the actual available electricity prices, we split the two countries in our model.

${ }^{4}$ A2A, Axpo Energia Spa, EDF Edison, ENI, EPH, GDF Suez, Iren Energia, Sorgenia, Elektroprivreda Bosne i Hercegovine (EPBIH), BEH, CEZ Electro Bulgaria (CEZ), Hrvatksa Elektroprivreda (HEP), Holding Slovenske Elektrarne (HSE), GEN Energija, Elektroprivreda Srbije (EPS), Electrica, Elektroprivreda Makedonije (ELEM), Elektroprivreda Crne Gore (EPCG), PPC, Protergia, MVM.

${ }^{5}$ Because Italy is modelled by 11 nodes, we approximate hydropower availabilities per node considering firms' hydropower fleet locations and regional hydropower production data from Terna (2013). 
Table 1: Technology availability factor (Schröder et al. 2013), operating costs, and emission rates

\begin{tabular}{|c|c|c|c|c|c|c|c|c|}
\hline $\begin{array}{ll}\text { Characteristic } & \text { Technology } \\
\end{array}$ & $\mathrm{NG}$ & Coal & Oil & CCGT & Nuclear & Lignite & Mixed & Hydro \\
\hline Availability factor $(\%)$ & 75 & 84 & 86 & 75 & 90 & 85 & 86 & 100 \\
\hline Operating cost (€/MWh) & 47.3 & 22 & 50 & 35.7 & 10 & 21 & 48 & 0 \\
\hline Emission rate (t/MWh) & 0.435 & 0.746 & 0.930 & 0.363 & 0 & 0.826 & 0.800 & 0 \\
\hline
\end{tabular}

When implemented, the ETS constraint is imposed only on the SEE-REM EU ETS participants in the electricity sector, whereas the actual EU ETS spans more countries and sectors (European Commission, 2018a). In effect, we assume that the leader manipulates a notional SEE-REM-only ETS price. This simplification is suitable for our purpose where we aim to assess the impact of strategic behaviour ceteris paribus instead of replicating what is happening in SEE-REM. On the other hand, in the leader-follower setting with market power only in the electricity market, the permit price is treated exogenously, thereby effectively serving as a carbon tax. The exogenous permit price assumption represents the upper limit of the impact that a permit price can have on activity in the SEE-REM part of ETS as it means that any changes in the SEE-REM ETS emissions would be offset elsewhere in the ETS.

\section{Results and Discussion}

\subsection{Scenario Description}

For the purpose of examining the effect of market power in both electricity and permit markets, we have three market settings:

- Perfect competition in both electricity and permit markets (PC).

- Stackelberg leader-follower setting (S-T) in which Enel is the leader with market power in the electricity market only, whereas the permit price is an exogenous carbon tax corresponding to the permit price from the respective PC scenario.

- Stackelberg leader-follower setting $(\mathrm{S})$ in which Enel has market power in both electricity and permit markets, whereas all other firms are price takers in both markets.

We examine the impact of the stringency of regulation in $\mathrm{PC}$ and $\mathrm{S}$ by considering four cases with a binding emission cap corresponding to an ETS part of SEE-REM emission reduction of 10\%-40\% compared to the baseline scenario. The baseline scenario is established by running PC and $\mathrm{S}$ without an emission cap and is labelled "PC-B0" and "S-B0," respectively. The scenarios with binding caps are labelled "B10"-“B40," which corresponds to the percentage ETS emission reduction. Finally, since each S-T scenario has a carbon tax equal to the permit price from the respective PC scenario, its label corresponds to the PC scenario from which the permit price is taken. We have a total of fourteen scenarios as given in Table 2, which are exogenous to the model and lead to various outputs calculated endogenously by the model, e.g., more or less use of certain technologies.

\subsection{Computational Issues}

For the PC scenarios, the problem instances solve QP (1)-97 in which all firms are treated as price takers. Such instances take a few seconds to solve to optimality with GAMS 24.8.3 using CPLEX 12.7.0.0. By contrast, the $\mathrm{S}$ scenarios solve instances of the MIQP in Appendix C.3 to a relative gap of $2.66 \%$ (on average) in approximately five minutes with the same software configuration.

Copyright (C) 2018 by the IAEE. All rights reserved. 
Table 2: Scenario description

\begin{tabular}{c|l}
\hline Scenario & \multicolumn{1}{c}{ Description } \\
\hline PC-B0 to PC-B40 & $\begin{array}{l}\text { Perfect competition with ETS cap equal to 0\%-40\% } \\
\text { reduction in emissions. } \\
\text { Stackelberg leader-follower with ETS cap equal to 0\%-40\% } \\
\text { reduction in emissions. } \\
\text { S-T-B10 to S-T-B40 }\end{array}$ \\
$\begin{array}{l}\text { Stackelberg leader-follower with carbon tax equal } \\
\text { to the respective PC scenario permit price. }\end{array}$ \\
\hline
\end{tabular}

Figure 2: Annual production in the ETS and non-ETS part of SEE-REM in PC scenarios

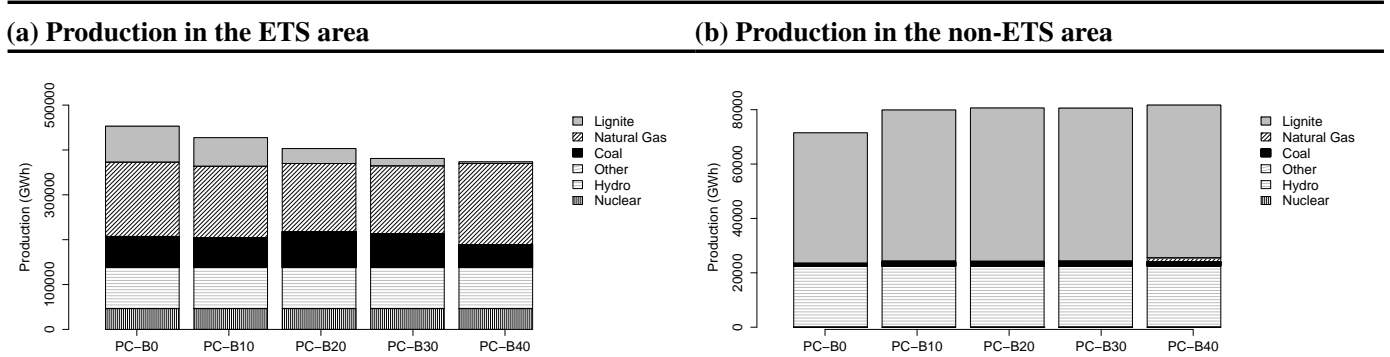

\subsection{Perfect Competition Analysis}

The ETS part of SEE-REM is where consumption and production are concentrated (Tables B-7,B-10 and B-12 and is a net importer of dirty electricity from the non-ETS part importing $2 \%-7 \%$ of its total consumption in PC-B0 to PC-40, respectively. A binding emission cap curbs ETS production (Figure 2a). The stringency of the cap has contrasting effects on different technologies, i.e., looser caps affect more expensive and cleaner technologies and vice versa. In fact, in scenarios PC-B10 to PC-B30, natural gas is the most affected as it is the highest-cost fuel. However, a tighter cap results in fuel switching through which cheaper and dirtier technologies in the generation mix are replaced by cleaner and more expensive ones. For example, in PC-B20 and PC-B30, coal production expands to replace declining lignite production. Similarly, in PC-B40, natural-gas production rebounds above the PC-B0 level as it replaces declining coal and lignite production. Despite fuel switching, the deficit between ETS production and consumption widens with a tighter cap leading to higher imports from the non-ETS area (Figure 3). Consequently, non-ETS production generally grows (Figure 2b) with the exception of PC-B30 where the effect of demand response in the non-ETS area offsets higher exports to the ETS area. Higher non-ETS production increases non-ETS emissions by between $17 \%$ and $20 \%$ in PC-B10 to PC-B40 compared to that in PC-B0, which leads to carbon leakage of $38.59 \%$ to $11.10 \%$ in PC-B10 to PC-B40, respectively (Table 9).

As a baseline, without any carbon policy in PC-B0, total production in SEE-REM is equal to $524,387 \mathrm{GWh}$, of which $86 \%$ is produced in the ETS area and $14 \%$ in the non-ETS area. Without the binding emission cap, the merit order of the most represented fossil fuels is given by lignite, coal, and natural gas from cheapest to most expensive, respectively, with proportions in the ETS generation mix of $18 \%, 15 \%$, and $36 \%$, respectively. By contrast, the non-ETS area heavily relies on lignite production accounting for ca. $67 \%$ of its total production. ETS consumption exceeds ETS production by $7,269 \mathrm{GWh}$, which is equal to the imports from the non-ETS area. This is not surprising given the abundance of resources in the non-ETS countries compared to the relatively small population. However, the higher emission intensity of non-ETS countries (on average $0.57 \mathrm{t} / \mathrm{MWh}$ compared to an average of 0.39 t/MWh in ETS countries) causes non-ETS (ETS) emissions account for 19\% (81\%) of total SEE-REM emissions. 
Figure 3: Annual net import by ETS from non-ETS and carbon leakage in PC scenarios

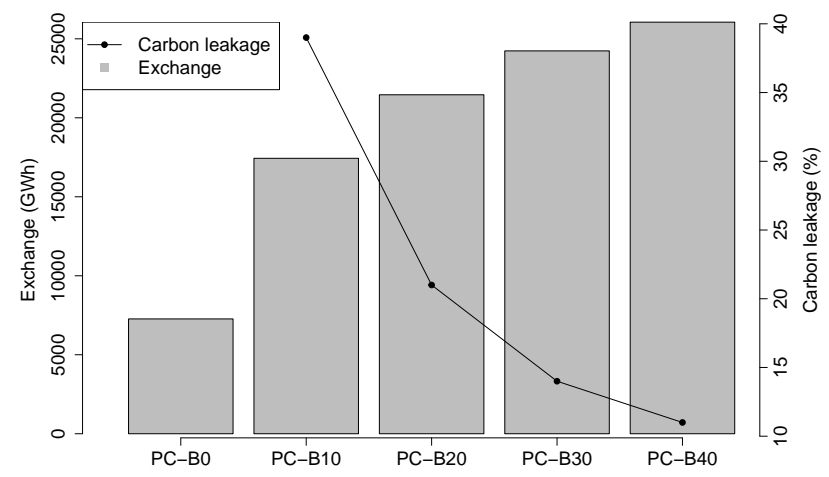

A moderate carbon cap of $142,255 \mathrm{kt}$ in PC-B20 results in a permit price of $€ 20.02 / \mathrm{t}$, which changes the merit order between coal and lignite, i.e., coal's marginal cost of production is now lower than lignite's. Due to a tighter cap, ETS natural-gas and lignite production decrease by $8.43 \%$ and $58.40 \%$, respectively, but ETS coal production increases by $16.58 \%$, thereby leading to an overall decline in ETS output of $10.99 \%$ relative to PC-B0. However, the deficit between production and consumption in the ETS area widens further compared to PC-B0 reaching 21,458 GWh. This increases non-ETS exports and emissions by $14,189 \mathrm{GWh}$ and 7,467 kt, respectively, compared to PC-B0 leading to a carbon leakage of $20.99 \%$. For comparison, carbon leakage under PC-B10 is $38.6 \%$.

With a stringent carbon cap of $106,692 \mathrm{kt}$ in PC-B40, the permit price is equal to $€ 35.77 / \mathrm{t}$, which alters the merit order such that lignite is the most expensive followed by coal and natural gas at parity. Consequently, overall ETS production drops by $17.5 \%$ compared to PC-B0. In particular, coal production drops by $25.81 \%$ and $36.37 \%$ compared to PC-B0 and PC-B20, respectively. Lignite production decreases to approximately $5 \%$ of the PC-B0 level. By contrast, natural-gas production increases by $19.25 \%$ and $9.48 \%$ compared to the PC-B20 and PC-B0 scenarios, respectively, as it replaces coal and lignite. However, ETS net imports increase and lead to more pressure on non-ETS firms to export. As non-ETS production expands by 10,186 GWh compared to PC-B0, carbon leakage is equal to $11.10 \%$.

As electricity prices incrementally increase and SEE-REM electricity consumption falls from 524,386 GWh in PC-B0 to 455,313 GWh in PC-B40, consumer surplus decreases by $21.24 \%$ in PC-B40 compared to PC-B0 (Table B-14). In addition, due to decreasing electricity consumption, the grid owner's merchandising surplus (MS) decreases by $19.81 \%$ in PC-B20 compared to PC-B0. However, in PC-B40, MS is above the PC-B20 level due to higher revenues associated with imports to expensive ETS nodes. Despite the higher abatement cost, producer surplus increases from PC-B0 to PC-B40 due to windfall profits of relatively cleaner and non-ETS firms. In fact, compared to PC-B0, in PC-B40, producer surplus increases by $34.45 \%$. In PC-B10 to PC-B40, social welfare includes revenues from emission permit sales, which increase incrementally from $€ 1$ billion in PC-B10 to almost three times more in PC-B30. Compared to PC-B30, revenues from emission permits in PC-B40 fall by $€ 135$ million as the fall in ETS production offsets a modest increase of $€ 4.02 / t$ in permit price. Nevertheless, the prevalent effect on social welfare is the declining consumer surplus dominating any increase in producer surplus and emission permit revenues. Consequently, total social welfare falls by $3.43 \%$ in PC-B40 compared to PC-B0. 


\subsection{Perfect Competition versus Stackelberg without Carbon Policy (PC-B0 and S-BO)}

In this section, we examine the impact of market power in SEE-REM in the absence of any carbon policy, i.e., scenarios PC-B0 and S-B0. First, we analyse the situation in Italy under PC-B0 because Italy is the only country in SEE-REM where Enel owns capacity and, thus, has the greatest impact. Second, we analyse the change in market outcomes resulting from the exercise of market power in Italy and the rest of SEE-REM by grouping the Italian nodes into four regions, viz., North $\left(n_{1}, n_{2}\right.$, and $\left.n_{7}\right)$, South $\left(n_{3}, n_{4}, n_{8}, n_{9}\right.$, and $\left.n_{10}\right)$, Sardinia $\left(n_{5}\right)$, and Sicily ( $n_{6}$ and $\left.n_{11}\right)$.

\subsubsection{Perfect Competition (PC-B0)}

In PC-B0, total electricity production in Italy amounts to approximately $60 \%$ of the total ETS production (Table 3), the bulk of which is located in the North (61\%), followed by the South (31\%), and the islands (jointly $8 \%$ ). The generation mix is given by natural gas $(57 \%)$, coal $(23 \%)$, and hydro (20\%). The North accounts for the majority of production, consumption, and imports, importing a net of $20,576 \mathrm{GWh}$, of which $81 \%$ is from the South and $19 \%$ is from Slovenia. By contrast, the South is the major net exporter, sending 16,614 GWh to the North and 4,550 GWh to Sardinia. In PC-B0, emissions in Italy are approximately $57 \%$ of SEE-REM ETS emissions (Table 4). Enel produces $83,085 \mathrm{GWh}$, which is approximately $30 \%$ of Italy's production. Enel predominantly generates from coal power plants (54\%), followed by natural gas (25\%). The majority of Enel's production is located in the North and the South (45\% in each region).

Table 3: Production per fuel type (GWh) in Italy in PC-Bo

\begin{tabular}{l|rrrr|r}
\hline \multicolumn{1}{c|}{ Technology } & Coal & Natural Gas & Other Fossil Fuels & Hydro & Total \\
\hline Nogion & 12,215 & 106,324 & 204 & 44,793 & 163,536 \\
of which Enel & 6,144 & 17,872 & 62 & 13,225 & 37,303 \\
of which fringe firms & 6,071 & 88,452 & 142 & 31,568 & 126,232 \\
South & 39,014 & 37,170 & - & 6,913 & 83,097 \\
of which Enel & 34,305 & - & - & 3,213 & 37,518 \\
of which fringe firms & 4,709 & 37,170 & - & 3,700 & 45,579 \\
Sardinia & 8,830 & 2,701 & 45 & 486 & 12,062 \\
of which Enel & 4,415 & - & - & 486 & 4,901 \\
of which fringe firms & 4,415 & 2,701 & 45 & - & 7,161 \\
Sicily & - & 7,473 & - & 584 & 8,057 \\
of which Enel & - & 2,778 & - & 584 & 3,362 \\
of which fringe firms & - & 4,695 & - & - & 4,695 \\
\hline Total & 60,059 & 153,668 & 249 & 52,776 & 266,752 \\
of which Enel & 44,864 & 20,650 & 62 & 17,509 & 83,085 \\
of which fringe firms & 15,195 & 133,018 & 187 & 35,268 & 183,667 \\
\hline
\end{tabular}

\subsubsection{Impact of Strategic Behaviour (S-B0)}

The leader manipulates the electricity market by adjusting its production quantities and anticipating the reaction of the fringe firms and the ISO at the lower level. Overall in Italy, Enel withholds a total of 5,146 GWh, of which 4,164 GWh is from natural gas and $919 \mathrm{GWh}$ from coal (Table 5 . Consequently, Enel raises electricity prices in Italy such that consumption drops by 1,557 GWh vis-à-vis PC-B0 (Table B-11). Fringe firms in Italy react to higher electricity prices and replace 75\% of the production withheld by Enel by expanding their production by 3,853 GWh, most of which comes from natural gas $(3,603 \mathrm{GWh})$. On a regional level, Enel withholds coal production (855 
Table 4: Consumption (GWh), net imports/exports (GWh), and emissions (kt) in Italy in perfect competition

\begin{tabular}{|c|c|c|c|c|c|}
\hline Region $\quad$ Scenario & PC-B0 & PC-B10 & PC-B20 & PC-B30 & PC-B40 \\
\hline Consumption & & & & & \\
\hline North & 184,112 & 180,201 & 175,360 & 170,453 & 168,668 \\
\hline South & 65,422 & 63,986 & 62,092 & 60,141 & 59,473 \\
\hline Sardinia & 16,612 & 16,245 & 15,799 & 15,350 & 15,196 \\
\hline Sicily & 8,025 & 7,849 & 7,616 & 7,377 & 7,295 \\
\hline Total & 274,171 & 268,281 & 260,868 & 253,322 & 250,631 \\
\hline \multicolumn{6}{|l|}{ Imports/Exports } \\
\hline North & 20,576 & 20,858 & 20,891 & 20,197 & 15,552 \\
\hline South & $-17,675$ & $-17,490$ & $-17,029$ & $-18,789$ & $-19,573$ \\
\hline Sardinia & 4,550 & 4,272 & 3,940 & 3,517 & 4,966 \\
\hline Sicily & -32 & -32 & -18 & -117 & -255 \\
\hline Total & 7,419 & 7,607 & 7,784 & 4,809 & 690 \\
\hline \multicolumn{6}{|l|}{ Emissions } \\
\hline North & 47,894 & 46,285 & 44,498 & 42,963 & 42,655 \\
\hline South & 42,597 & 42,009 & 41,154 & 41,085 & 36,807 \\
\hline Sardinia & 7,610 & 7,557 & 7,510 & 7,500 & 6,231 \\
\hline Sicily & 2,713 & 2,649 & 2,559 & 2,508 & 2,529 \\
\hline Total & 100,814 & 98,500 & 95,722 & 94,057 & 88,223 \\
\hline
\end{tabular}

$\mathrm{GWh})$ in the South and natural-gas production $(4,722 \mathrm{GWh})$ in the North. As consumption in the South and the North declines, follower firms in the South reduce their production substantially $(7,434$ GWh), which results in a decrease in exports to the North by $8,795 \mathrm{GWh}$. By contrast, in the North, higher electricity prices entice the fringe firms' natural-gas production, which increases by 12,209 GWh. The contrasting effect on fringe firms' natural-gas production in the South and in the North can be explained by Enel's strategy to choke off fringe firms' production in the South in order to raise electricity prices further in the North allowing it to earn higher profits locally.

Enel's strategic behaviour affects other ETS countries' prices through imports but not directly via capacity withholding. In particular, consumption in the ETS (excluding Italy) drops by $186 \mathrm{GWh}$ (Table B-13 curbing the fringe firms' production by $546 \mathrm{GWh}$, which increases ETS (excluding Italy) imports by $360 \mathrm{GWh}$. This change in imports reverses the position of ETS (excluding Italy) countries from net exporters to net importers. On the other hand, producers located in the non-ETS countries receive a signal from higher ETS electricity prices and, therefore, increase their production by $98 \mathrm{GWh}$, thereby covering the net increase in total ETS (including Italy) imports. The actions of the dominant producer in S-B0 result in electricity market inefficiencies as Enel promotes less cost-effective, albeit cleaner, production, which reduces ETS emissions by $989 \mathrm{kt}$, i.e., a decrease of $0.56 \%$ compared to PC-B0. Yet, the change in import/export patterns in the entire ETS area increases net ETS imports from the non-ETS area by $96 \mathrm{GWh}$ leading to $86 \mathrm{kt}$ higher non-ETS emissions compared to PC-B0. In other words, $8.7 \%$ of the emission reduction achieved in the ETS area is relocated into the non-ETS area as a consequence of Enel's strategic behaviour.

Through the manipulation of electricity prices, Enel increases its profit by $€ 13$ million, $1.05 \%$ above PC-B0 (Table 6). As other producers in the market also benefit from higher electricity prices, producer surplus rises to $€ 216$ million (3.57\%) above its PC-B0 level. Conversely, lower ETS consumption and higher electricity prices decrease consumer surplus by $€ 248$ million $(0.73 \%)$ vis-à-vis PC-B0 (Table B-14). MS is higher in S-B0 compared to PC-B0 despite lower total production in S-B0 due to higher exports from the cheap non-ETS producers to a more expensive ETS area. 
Table 5: Change in production (GWh) from PC-B0 in Italy in S-B0

\begin{tabular}{l|rrcr|r}
\hline \multicolumn{1}{c|}{ Technology } & Coal & Natural Gas & Other Fossil Fuels & Hydro & Total \\
Region & - & 7,486 & 181 & - & 7,667 \\
\hline North & - & $-4,722$ & -62 & - & $-4,784$ \\
of which Enel & - & 12,209 & 243 & - & 12,452 \\
of which fringe firms & -855 & $-7,434$ & - & - & $-8,290$ \\
South & -855 & - & - & - & -855 \\
of which Enel & - & $-7,434$ & - & - & $-7,434$ \\
of which fringe firms & -64 & -11 & 7 & - & -68 \\
Sardinia & -64 & - & - & - & -64 \\
of which Enel & - & -11 & 7 & - & -4 \\
of which fringe firms & - & -602 & - & -1 & -603 \\
Sicily & - & 558 & - & - & $-1,161$ \\
of which Enel & - & $-1,161$ & - & -1 & $-1,293$ \\
of which fringe firms & -919 & -561 & 188 & -1 & $-5,146$ \\
\hline Total & -919 & $-4,164$ & -62 & - & 3,853 \\
of which Enel & - & 3,603 & 250 & & 557 \\
of which fringe firms & & & & -19 \\
\hline
\end{tabular}

Finally, as a result of strategic behaviour, overall social welfare decreases by $€ 24$ million $(0.06 \%)$ from its PC-B0 level.

Table 6: Strategic producer's profit $(k €)$

\begin{tabular}{l|rrrrr}
\hline \multicolumn{1}{c|}{ Scenario } & \multicolumn{1}{c}{ B0 } & \multicolumn{1}{c}{ B10 } & \multicolumn{1}{c}{ B20 } & \multicolumn{1}{c}{ B30 } & \multicolumn{1}{c}{ B40 } \\
\hline Setting & $1,285,520.55$ & $1,191,826.37$ & $1,056,901.47$ & $915,116.14$ & $869,808.46$ \\
PC & $13,491.77$ & $15,408.45$ & $15,192.45$ & $30,679.90$ & $45,623.22$ \\
S-T ( change from PC) & $1.05 \%$ & $1.29 \%$ & $1.44 \%$ & $3.35 \%$ & $5.25 \%$ \\
\% change & $13,491.77$ & $25,579.51$ & $35,451.86$ & $32,101.86$ & $38,087.96$ \\
S (change from PC) & $1.05 \%$ & $2.15 \%$ & $3.35 \%$ & $3.51 \%$ & $4.38 \%$ \\
\% change & & & & &
\end{tabular}

\subsection{Perfect Competition versus Stackelberg with a Moderate Carbon Policy (PC-B20, S-T-B20, and S-B20)}

Analogous to Figure 2, Figures 4 and 5 illustrate the impact of tightening the emission cap on the generation mix in the S-T and S scenarios, respectively. We next discuss the impact of market power under a moderate ETS carbon policy.

\subsubsection{Perfect Competition (PC-B20)}

As a result of a moderate carbon cap, production in Italy (Table 7) is curbed by $13,667 \mathrm{GWh}$ in PC-B20 vis-à-vis PC-B0. For permit prices in the range of $€ 8.64-€ 31.75 / t$ (covering PC-B10 and PC-B30 as well as PC-B20), since natural gas remains the most expensive technology in Italy, the proportion of natural gas in the generation mix decreases leaving a larger share to coal. Consumption drops by 13,302 GWh in PC-B20 compared to that in PC-B0. The reduction in consumption is less than that in production in PC-B20 as Italy increases imports from cheaper nodes, i.e., Slovenia and Greece. Emissions in Italy decrease by 5,092 kt from their PC-B0 levels. As the largest concentration of natural-gas production within Italy is in the North, the North is the most affected region by the production reduction. Enel shrinks its natural-gas production by 5,279 GWh from its PC-B0 level. 
Figure 4: Annual production in the ETS and non-ETS part of SEE-REM in S-T scenarios

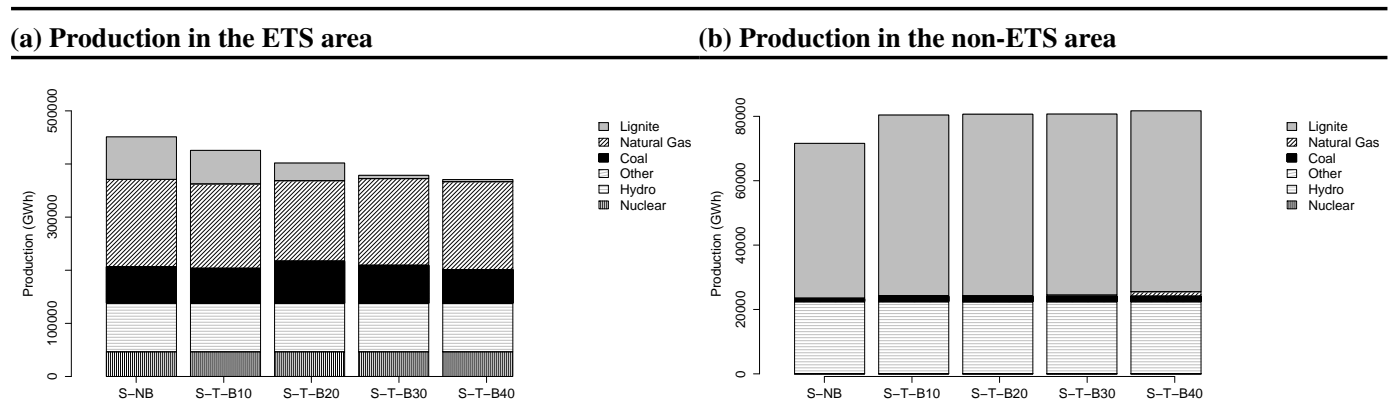

Figure 5: Annual production in the ETS and non-ETS part of SEE-REM in S scenarios

(a) Production in the ETS area

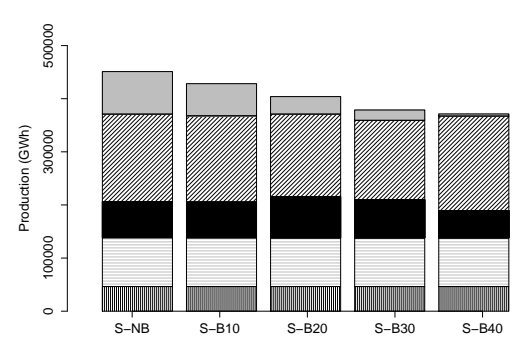

(b) Production in the non-ETS area

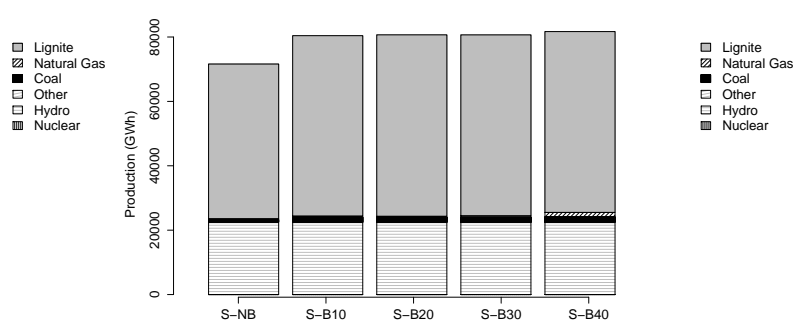

\subsubsection{Impact of Market Power in the Electricity Market (S-T-B20)}

With market power in the electricity market under a moderate carbon cap, Enel adopts the same strategy as in S-B0 coal-wise and manipulates the electricity market through the most important exchange link, i.e., between the North and the South, by withholding capacity in the regions where it has the largest share, viz., the South and the islands (Table 8). Enel holds back production from the South and the islands to choke off fringe firms' production in the South and Sardinia. In Sicily, fringe firms react by increasing production, but this only partly replaces Enel's withholding and boosts imports. As the islands import more from the South and the South's production decreases, exports to the North are reduced, thus, driving up electricity prices. Contrary to S-B0, Enel uses this outcome to expand its natural-gas production in the North, thereby profiting locally. A possible explanation for this change in strategy is the increased availability of unused natural-gas plants compared to S-B0 due to the introduction of the carbon tax, which curbs primarily natural-gas production. Hence, the leader deploys this excess capacity to limit fringe output in the North under S-T-B20.

Higher electricity prices curb consumption in Italy by $1,185 \mathrm{GWh}$ in S-T-B20 compared to that in PC-B20. Production, however, shrinks to a lesser extent, decreasing by $865 \mathrm{GWh}$ in S-T-B20 vis-à-vis PC-B20. Enel's strategic behaviour reduces the deficit between production and consumption in Italy, thereby lowering imports. In addition, since Enel's strategy results in the replacement of coal production by natural gas, emissions in Italy decrease by $772 \mathrm{kt}$ in S-T-B20 from their PC-B20 levels.

The effect of higher electricity prices nominally carries over to other ETS countries. In fact, consumption in other ETS countries falls by $157 \mathrm{GWh}$ in S-T-B20 compared to the PC-B20 level. On the other hand, production in the other ETS countries is more affected, decreasing by $509 \mathrm{GWh}$ in S-T-B20 compared to that in PC-B20. Therefore, the deficit in the ETS area (excluding Italy) widens compared to the PC scenarios. This is covered by the non-ETS producers by re-directing imports not required by Italy, increasing their production, and selling electricity not consumed in the domestic market due to higher electricity prices. In this way, emissions in the ETS area (including Italy) drop 
Table 7: Production per fuel type (GWh) in Italy in PC-B20

\begin{tabular}{l|rrrr|r}
\hline \multicolumn{1}{c|}{ Technology } & Coal & Natural Gas & Other Fossil Fuels & Hydro & Total \\
\hline Region & 12,215 & 97,462 & - & 44,793 & 154,469 \\
of which Enel & 6,144 & 10,477 & - & 13,225 & 29,847 \\
of which fringe firms & 6,071 & 86,984 & - & 31,568 & 124,623 \\
South & 39,014 & 33,194 & - & 6,913 & 79,122 \\
of which Enel & 34,305 & - & - & 3,213 & 37,518 \\
of which fringe firms & 4,709 & 33,194 & - & 3,700 & 41,604 \\
Sardinia & 8,830 & 2,543 & - & 486 & 11,859 \\
of which Enel & 4,415 & - & - & 486 & 4,901 \\
of which fringe firms & 4,415 & 2,543 & - & - & 6,958 \\
Sicily & - & 7,051 & - & 584 & 7,635 \\
of which Enel & - & 4,956 & - & 584 & 5,540 \\
of which fringe firms & - & 2,095 & - & - & 2,095 \\
\hline Total & 60,059 & 140,249 & - & 52,776 & 253,085 \\
of which Enel & 44,864 & 15,433 & - & 17,509 & 77,806 \\
of which fringe firms & 15,195 & 124,816 & - & 35,268 & 175,279 \\
\hline
\end{tabular}

by $231 \mathrm{kt}$ in S-T-B20 below PC-B20 levels (Table B-8). By contrast, non-ETS emissions increase by $19 \mathrm{kt}$ in S-T-B20 above PC-B20 levels. However, since the reduction in ETS emissions compared to PC-B0 is the dominant effect offsetting the non-ETS emissions increase, carbon leakage is below the respective perfectly competitive scenarios (Table 9 ).

By manipulating the electricity market in Italy, Enel earns a profit of $€ 15$ million (1.44\%) in S-T-B20 above PC-B20 levels. Due to higher electricity prices and lower consumption, consumer surplus decreases $€ 224$ million below the PC-B20 level. Higher electricity prices benefit the producers resulting in an increase in aggregate profit $€ 188$ million in excess of the PC-B20 level. MS increases $€ 18$ million compared to the PC-B20 level since there is more exchange between ETS and non-ETS at a higher price differential. Due to lower ETS production, C\&T permit revenues decline $€ 21$ million compared to the PC-B20 level. Strategic behaviour has a welfare-decreasing effect whereby social welfare declines by $€ 39$ million compared to the PC-B20 level.

\subsubsection{Impact of Market Power in Both Electricity and Permit Markets (S-B20)}

With market power in both the electricity and the permit markets under a moderate carbon policy, the dominant producer can manipulate an additional variable vis-à-vis the carbon tax scenarios, i.e., the endogenously determined C\&T permit price. Since the leader is a buyer of permits, it engages in a monopsonistic strategy to push the permit price down. For this purpose, the leader withholds more coal compared to S-T-B20 because coal has more impact on the permit price due to its higher pollution content. Natural-gas-wise, the leader's strategy depends on the availability of fringe firms' natural-gas production. Under a moderate carbon cap in S-B20, the leader expands natural-gas production as in S-T-B20. In fact, the leader attempts to withhold more coal and to expand more gas production under S-B20 vis-à-vis S-T-B20 in order to lower the permit price.

In an attempt to lower the C\&T permit price, Enel withholds coal production by $3,934 \mathrm{GWh}$ in S-B20 compared to that in PC-B20 (Table 10). As a result, in S-B20, Enel brings the C\&T permit price below PC-B10 and PC-B20 levels resulting in savings of approximately $€ 2 /$ t. In S-B20, by withholding more coal production in the South, Enel raises average electricity prices in the South compared to S-T-B20. Higher electricity prices in the South at a lower or equal cost of abatement compared to S-T-B20 entice fringe firms' natural-gas production in the South, thus increasing the flow on the line between the South and the North. Consequently, average electricity prices in the North are below S-T-B20 levels, thereby curbing fringe firms' gas production in the North. 
Table 8: Change in production (GWh) from PC-B20 in Italy in S-T-B20

\begin{tabular}{l|crrr|r}
\hline \multicolumn{1}{c}{ Technology } & Coal & Natural Gas & Other Fossil Fuels & Hydro & Total \\
\hline North & - & 9,505 & - & - & 9,505 \\
of which Enel & - & 4,437 & - & - & 4,437 \\
of which fringe firms & - & 5,068 & - & - & 5,068 \\
South & -898 & $-7,233$ & - & - & $-8,131$ \\
of which Enel & -898 & - & - & - & -898 \\
of which fringe firms & - & $-7,233$ & - & - & $-7,233$ \\
Sardinia & -302 & $-1,488$ & - & - & $-1,790$ \\
of which Enel & -302 & $-1,488$ & - & - & -302 \\
of which fringe firms & - & -448 & - & - & $-1,488$ \\
Sicily & - & -787 & - & -1 & -450 \\
of which Enel & - & 339 & - & - & -788 \\
of which fringe firms & - & 336 & - & -1 & -865 \\
\hline Total & $-1,200$ & 3,650 & - & -1 & 2,449 \\
of which Enel & $-3,314$ & - & - & $-3,314$ \\
of which fringe firms & - & & - & - & - \\
\hline
\end{tabular}

Table 9: Carbon leakage (\%) - top and permit price (€/t) - bottom

\begin{tabular}{|c|c|c|c|c|}
\hline $\begin{array}{ll}\text { Setting } & \text { Scenario }\end{array}$ & B10 & B20 & B30 & B40 \\
\hline $\mathrm{PC}$ & 38.59 & 20.99 & 13.81 & 11.10 \\
\hline S-T & 38.00 & 20.47 & 12.34 & 11.72 \\
\hline S & 40.62 & 20.95 & 13.84 & 11.04 \\
\hline 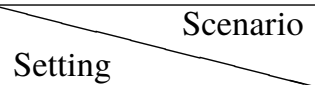 & B10 & B20 & B30 & B40 \\
\hline $\mathrm{PC}$ & 8.64 & 20.02 & 31.75 & 35.77 \\
\hline S & 6.55 & 17.81 & 31.75 & 35.77 \\
\hline
\end{tabular}

In contrast to Italy, in S-B20, the dominant effect on other ETS countries is the lower permit price, which entices production from coal and natural gas (Table B-8) and brings electricity prices below the respective perfectly competitive levels. As a result, ETS electricity consumption grows by 1,835 GWh in S-B20 above the PC-B20 level. Since emissions from producers located in the ETS cannot exceed the cap, in order to offset higher emissions from coal and natural gas, follower firms reduce lignite production. Essentially, firms in the ETS (excluding Italy) resort to fuel switching in order to meet part of the ETS excess electricity consumption over the PC-B20 level. The remainder of the excess ETS consumption is met by non-ETS firms that increase their exports into the ETS area (excluding Italy). Given the relatively low capacity of the non-ETS producers, in S-B20, as they choose to sell more electricity in the ETS area, non-ETS prices increase. Consumers in the non-ETS respond by decreasing their consumption by $72 \mathrm{GWh}$, which increases unregulated electricity available for export to the ETS by $114 \mathrm{GWh}$. Since Italy reduces its imports by $139 \mathrm{GWh}$, non-ETS firms can export $253 \mathrm{GWh}$ more to the rest of the ETS. ETS emissions fall by $791 \mathrm{kt}$, which, as a result of limited fuel switching, is $198 \mathrm{kt}$ less than that in S-B0. On the other hand, due to lower available capacity, non-ETS emissions increase only by 30 kt, 56 kt less vis-à-vis S-B0, thus, maintaining similar levels as PC-B20.

An additional variable available for manipulation provides Enel with an extra opportunity to increase its profit. In fact, Enel raises its profit in S-B20 to $€ 35$ million over that in PC-B20. The increase is higher compared to the respective carbon tax scenarios. Since ETS producers benefit from a lower abatement cost in S-B20 and, in Italy, higher electricity prices, producer surplus increases by $€ 300$ million compared to the PC-B20 level. The increase in producer surplus is well above the 
Table 10: Change in production (GWh) from PC-B20 in Italy in S-B20

\begin{tabular}{l|crrr|r}
\hline \multicolumn{1}{c|}{ Technology } & Coal & Natural Gas & Other Fossil Fuels & Hydro & Total \\
\hline Region & -223 & -491 & 27 & - & -687 \\
North which Enel & -223 & 5,007 & 14 & - & 4,798 \\
of which fringe firms & - & $-5,498$ & 13 & - & $-5,485$ \\
South & $-3,206$ & 5,427 & - & - & 2,222 \\
of which Enel & $-3,206$ & - & - & - & $-3,206$ \\
of which fringe firms & - & 5,427 & - & - & 5,427 \\
Sardinia & -505 & $-1,271$ & - & - & $-1,776$ \\
of which Enel & -505 & - & - & - & -505 \\
of which fringe firms & - & $-1,271$ & - & - & $-1,271$ \\
Sicily & - & -483 & - & - & -483 \\
of which Enel & - & $-1,884$ & - & - & $-1,884$ \\
of which fringe firms & - & 1,401 & - & - & 1,401 \\
\hline Total & $-3,934$ & 3,182 & 27 & - & -724 \\
of which Enel & $-3,934$ & 3,123 & 14 & - & -797 \\
of which fringe firms & - & 59 & 13 & - & 73 \\
\hline
\end{tabular}

increase in S-T-B20. In relation to consumer surplus, we have two competing effects, i.e., the increase in electricity prices in Italy and the decrease in electricity prices in the rest of ETS and some non-ETS countries. The former is prevalent in S-B20, leading to consumer surplus below the PC-B20 level. However, consumer surplus is well above that in S-T-B20. MS decreases in S-B20 compared to that in PC-B20 as the price differential between the ETS and non-ETS areas decreases. C\&T permit revenue is lower in S-B20 compared to that in PC-B20 and S-T-B20 due to lower C\&T permit prices. Hence, Enel's strategic behaviour lowers social welfare by $€ 62$ million compared to that in PC-B20.

\subsection{Perfect Competition versus Stackelberg with a Stringent Carbon Policy (PC-B40, S-T-B40, and S-B40)}

\subsubsection{Perfect Competition (PC-B40)}

At an allowance price of $€ 35.77 / \mathrm{t}$ resulting from a $40 \%$ reduction in ETS carbon emissions, natural gas reaches parity with coal. This change in the merit order shifts production within the ETS towards natural-gas-rich firms located in Italy, thereby increasing the proportion of Italian production in the ETS to $67 \%$. Due to higher electricity prices, consumption falls to $250,631 \mathrm{GWh}$, a decrease of $8.6 \%$ vis-à-vis PC-B0. A considerable drop in emissions occurs because of the switch to natural gas with emissions equal to $88,223 \mathrm{kt}$, i.e., a decrease of $12.5 \%$ compared to that in PC-B0. Another consequence of the increased production from natural gas is the import/export pattern. First, imports from Slovenia decline to $1,918 \mathrm{GWh}$ and are the lowest among PC scenarios. Second, the flow on the line between Italy and Greece is reversed whereby Italy now exports 1,228 GWh of electricity to Greece. In the specific case of Enel (Table 11), since its production is mostly generated from coal, the cut in coal production offsets the increase in natural-gas production resulting in a total production cut of 21,785 GWh compared to that in PC-B0.

\subsubsection{Impact of Market Power in the Electricity Market (S-T-B40)}

As Italy gains a larger share in total ETS production due to the cost parity between coal and natural gas, Enel gains more leverage for manipulating the market partly by reinstating coal production, which comprises most of its production. In contrast to the other S-T scenarios (Table 12), Enel expands its coal production in the South and in the North in order to set equilibrium prices. While the fringe 
firms' reaction is similar to S-T-B20 natural-gas-wise resulting in production reduction of 15,052 GWh compared to that in PC-B40, higher equilibrium prices entice fringe firms' coal production. Enel's strategy in the South and the islands affects the flows in Italy in a similar way to S-T-B20, thus allowing Enel to profit locally in the North by partly replacing fringe firms' natural-gas production.

Table 11: Production per fuel type (GWh) in Italy in PC-B40

\begin{tabular}{l|rrrr|r}
\hline \multicolumn{1}{c}{ Technology } & Coal & Natural Gas & Other Fossil Fuels & Hydro & Total \\
\hline North & 8,703 & 99,619 & - & 44,793 & 153,116 \\
of which Enel & 5,289 & 10,865 & - & 13,225 & 29,380 \\
of which fringe firms & 3,414 & 88,754 & - & 31,568 & 123,736 \\
South & 27,737 & 44,396 & - & 6,913 & 79,046 \\
of which Enel & 23,379 & - & - & 3,213 & 26,592 \\
of which fringe firms & 4,358 & 44,396 & - & 3,700 & 52,453 \\
Sardinia & 7,034 & 2,710 & - & 486 & 10,230 \\
of which Enel & 4,415 & - & - & 486 & 4,901 \\
of which fringe firms & 2,619 & 2,710 & - & - & 5,329 \\
Sicily & - & 6,966 & - & 584 & 7,550 \\
of which Enel & - & 4,842 & - & 584 & 5,426 \\
of which fringe firms & - & 2,124 & - & - & 2,124 \\
\hline Total & 43,474 & 153,691 & - & 52,776 & 249,942 \\
of which Enel & 33,084 & 15,708 & - & 17,509 & 66,300 \\
of which fringe firms & 10,391 & 137,984 & - & 35,268 & 183,642 \\
\hline
\end{tabular}

Table 12: Change in production (GWh) from PC-B40 in Italy in S-T-B40

\begin{tabular}{|c|c|c|c|c|c|}
\hline $\begin{array}{ll}\text { Region } & \text { Technology }\end{array}$ & Coal & Natural Gas & Other Fossil Fuels & Hydro & Total \\
\hline North & 2,917 & 335 & - & - & 3,252 \\
\hline of which Enel & 261 & 3,213 & - & - & 3,473 \\
\hline of which fringe firms & 2,656 & $-2,878$ & - & - & -221 \\
\hline South & 5,549 & $-11,029$ & - & - & $-5,480$ \\
\hline of which Enel & 5,197 & - & - & - & 5,197 \\
\hline of which fringe firms & 352 & $-11,029$ & - & - & $-10,677$ \\
\hline Sardinia & 992 & -776 & - & - & 216 \\
\hline of which Enel & -804 & - & - & - & -804 \\
\hline of which fringe firms & 1,796 & -776 & - & - & 1,020 \\
\hline Sicily & - & $-1,048$ & - & - & $-1,048$ \\
\hline of which Enel & - & -678 & - & - & -678 \\
\hline of which fringe firms & - & -370 & - & - & -370 \\
\hline Total & 9,459 & $-12,518$ & - & - & $-3,060$ \\
\hline of which Enel & 4,654 & 2,534 & - & - & 7,189 \\
\hline of which fringe firms & 4,804 & $-15,053$ & - & - & $-10,249$ \\
\hline
\end{tabular}

Average electricity prices climb above PC-B40 levels in most countries across SEE-REM such that electricity consumption in ETS falls by $2,843 \mathrm{GWh}$ and in non-ETS by $38 \mathrm{GWh}$. Higher electricity prices provide an opportunity for ETS (excluding Italy) lignite and coal plants to reinstate their production partly, which increases by $276 \mathrm{GWh}$ and 2,611 GWh, respectively, cutting out natural-gas production by 2,720 GWh vis-à-vis PC-B40 (Table B-10). Consequently, the rest of ETS net imports decline by $353 \mathrm{GWh}$ and emissions increase by 1,188 kt compared to PC-B40. Since non-ETS firms react to higher prices in the ETS area, non-ETS production increases by $14 \mathrm{GWh}$, exports by $52 \mathrm{GWh}$, and emissions by $6 \mathrm{kt}$. Leakage to the non-ETS part of SEE-REM is equal to 
$11.72 \%, 0.62$ percentage points above the PC-B40 level due to a smaller reduction in ETS emissions in S-T-B40. In conclusion, a carbon tax of $€ 35.77 / \mathrm{t}$ has detrimental consequences for SEE-REM emissions in the presence of market power resulting in total SEE-REM emissions 3,706 kt above the PC-B40 level.

In S-T-B40, Enel boosts its profit by $€ 45.6$ million or $5.25 \%$ more than in PC-B40. The increase in electricity prices is damaging for consumer surplus, which decreases by $€ 440$ million compared to that in PC-B40. On the other hand, producer surplus climbs $€ 415$ million above the PC-B40 level. MS increases due to the higher price differential between ETS and non-ETS countries, and C\&T permit revenues grow due to higher ETS emissions. The latter has the crucial impact on social welfare increasing it by $€ 113$ million vis-à-vis PC-B40.

\subsubsection{Impact of Market Power in Both Electricity and Permit Markets (S-B40)}

In S-B40, Enel's strategy for raising electricity prices is similar to that in S-T-B40 (Table 13). However, since Enel does not want to push the permit price above the PC-B40 level, it expands coal production to a lesser extent than in S-T-B40. In contrast to S-T-B40, fringe firms' coal production decreases as in S-B40 there is a cap on ETS emissions. However, similar to S-B20, fringe firms' natural-gas production in the South increases, thereby sending more electricity to the North. In the North, Enel chokes off fringe firms' natural-gas production and partly replaces it with its own in order to profit locally.

Table 13: Change in production (GWh) from PC-B40 in Italy in S-B40

\begin{tabular}{|c|c|c|c|c|c|}
\hline $\begin{array}{ll}\text { Region } & \text { Technology }\end{array}$ & Coal & Natural Gas & Other Fossil Fuels & Hydro & Total \\
\hline North & $-1,009$ & $-7,958$ & - & - & $-8,967$ \\
\hline of which Enel & -660 & 5,559 & - & - & 4,900 \\
\hline of which fringe firms & -349 & $-13,517$ & - & - & $-13,866$ \\
\hline South & 2,696 & 3,874 & - & - & 6,569 \\
\hline of which Enel & 4,920 & - & - & - & 4,920 \\
\hline of which fringe firms & $-2,224$ & 3,874 & - & - & 1,650 \\
\hline Sardinia & $-1,473$ & -623 & - & -5 & $-2,106$ \\
\hline of which Enel & $-1,395$ & - & - & -5 & $-1,406$ \\
\hline of which fringe firms & -77 & -623 & - & - & -700 \\
\hline Sicily & - & 732 & - & - & 732 \\
\hline of which Enel & - & -98 & - & - & -98 \\
\hline of which fringe firms & - & 829 & - & - & 829 \\
\hline Total & 214 & $-3,975$ & - & -5 & $-3,766$ \\
\hline of which Enel & 2,865 & 5,462 & - & -5 & 8,321 \\
\hline of which fringe firms & $-2,651$ & $-9,437$ & - & - & $-12,087$ \\
\hline
\end{tabular}

Due to a considerable decrease in Italy's emissions, production shifts towards the rest of ETS and increases by 1,397 GWh compared to PC-B40 (Table B-10). Most of the production is generated from natural gas as the cap on emissions forces cleaner production in comparison to S-T-B40. In fact, total ETS emissions are $593 \mathrm{kt}$ lower than those in PC-B40 and 4,293 kt lower than those in S-T-B40. In addition, given such a substantial increase in ETS (excluding Italy) production, non-ETS production remains unvaried. However, non-ETS firms decide to sell a larger part of their production to the ETS, but this derives from a decrease in non-ETS consumption. Therefore, non-ETS emissions remain unvaried despite the increase in exports to the ETS of $56 \mathrm{GWh}$. Finally, considering this together with a decline in ETS emissions, it is not surprising that carbon leakage (11.04\%) is somewhat lower than in PC-B40.

Enel's ability to manipulate the market is also echoed in its profit, which increases by $€ 38$ million compared to that in PC-B40, i.e., the largest increment in both amount and percentage terms 
in Enel's profit is associated with the tightest cap. Nevertheless, the increment is smaller compared to that in S-T-B40. One possible explanation is that the unwillingness to drive up the permit price and the limit on emissions given by the cap in S-B40 bound Enel's ability to substitute coal for natural gas compared to S-T-B40. In relation to social welfare, the effect on the specific items is similar to S-T-B40 with the exception of the C\&T permit revenues. Particularly, consumer surplus is the most negatively affected item falling by $€ 375$ million vis-à-vis PC-B40. Producers benefit from higher electricity prices with their aggregate profit climbing $€ 343$ million above the PC-B40 level. MS is $€ 13$ million higher as a result of moving more electricity towards expensive nodes in Italy in comparison with that in S-T-B40. In contrast to S-T-B40, C\&T permit revenues fall due to lower ETS production and result in an amount $€ 21$ million below PC-B40 levels. The overall effect on social welfare is negative, driving it down by $€ 39$ million vis-à-vis PC-B40.

\section{Conclusions}

The consequences of market power in electricity markets are well known and documented in the literature. However, electricity market outcomes can also be affected by market power exercised in C\&T systems. Since there is an increasing number of regional C\&T systems appearing as part of the global action against climate change, there is a growing need for understanding how electricity and C\&T permit markets can interact when subject to market power in terms of consequences for carbon emissions and leakage.

For this purpose, we develop a bi-level model of SEE-REM as a regional electricity market comprising EU member states subject to the EU ETS and non-EU countries exempt from it. In order to examine the effects of market power in electricity and permit markets on market outcomes, we specify three market settings, viz., perfectly competitive electricity and C\&T permit markets, imperfectly competitive electricity market where firms are price takers in the C\&T permit market, and imperfectly competitive electricity and C\&T permit markets. We find that under perfect competition, between 11\%-39\% of ETS emission reduction can be leaked into the non-ETS part of SEE-REM. Despite higher non-ETS production and emissions enticed by higher electricity prices resulting from the exercise of market power in the electricity market, carbon leakage is lower as ETS emissions are curbed due to strategic withholding. The contrary is true when the leader's dominant technology becomes the marginal technology, which results in the expansion of its dirty production and worsens the environmental situation compared to perfect competition. The exercise of market power in both markets generally results in higher ETS emissions and carbon leakage compared to the case with market power only in the electricity market as it entices more fringe firms' production due to a lower abatement cost. Under a $20 \%$ emission reduction, the marginal technology is natural gas, which means that Enel withholds coal (its dominant technology) in order to raise the electricity price and to lower the permit price. This is in contrast to standard microeconomic theory that indicates that, ignoring market power in the permit market, producers should withhold output from marginal units when attempting to push up prices. Moreover, Enel withholds coal to a greater extent than under the analogous setting where it has market power in the electricity market only in order to lower the permit price. However, when the leader's dominant technology becomes the marginal technology, the expansion of dirty production is limited by the effect that it might have on the permit price, thus improving environmental outcomes at a cost of lower profits. This is because under a $40 \%$ emission reduction, the marginal technology is coal, which induces Enel to expand coal production in order to raise the electricity price by driving out the Italian fringe producers. In comparison to the analogous setting where Enel has market power in the electricity market only, it expands coal production to a lesser extent in order to avoid increasing the permit price.

In general, the sustainable energy transition with greater reliance on variable renewable energy sources will provide more leverage to firms that have flexible production, viz., gas-fired plants, hydro reservoirs, and storage units, in their portfolios (Tangerås and Mauritzen, 2018). In the case of 
SEE-REM, a dominant firm with such a portfolio could manipulate both electricity and permit prices to its advantage, thereby possibly weakening the intent of carbon policy. Similar incentives may arise in interconnected power systems with overlapping carbon policies, e.g., in the Nordic region bordering Russia, at the New York and Québec interface, and in the PJM Interconnection where the Regional Greenhouse Gas Initiative (RGGI) may not apply. By developing similar models to identify risks to environmental goals resulting from market power, researchers could propose countervailing mechanisms in order to prevent such undesirable outcomes.

The findings in this paper are subject to some overarching limitations. First, we conduct a short-term analysis without the possibility of investment or retrofitting. Second, we assume that renewable generation is operating at its maximum availability, whereas the quantity of renewables available could play an important role on the dispatch of some fossil-fuel-based technologies. Third, the value chosen for point elasticity could either over- or under-estimate the leader's ability to exercise market power. For reference, a perfectly competitive case with fixed net demand in Višković et al. (2017) did not significantly affect the results concerning relative leakage. Furthermore, under a fixed demand, the dominant firm's ability to manipulate the electricity price may be overstated as its withholding is not offset by any demand response. Thus, our analysis may be considered as a conservative study of the impact of market power. Fourth, the representation of variability in demand and renewable production could be bolstered through the use of clustering without adding to the computational burden of the problem instances (Reichenberg et al. 2018).

Going forward, since the leader affects outcomes in Italy where it owns capacity more than other ETS countries and, thus, indirectly non-ETS countries, it would be relevant to investigate how the effects of market power could spill over to the non-ETS directly through the link Italy-Montenegro currently under construction (ENTSO-E, 2016). In addition, our analysis shows that the leader has the incentive to lower the C\&T permit price in order to decrease its marginal cost, whereas a higher C\&T permit price offers more incentives for non-ETS firms to export to the ETS. These incentives would be in conflict if a leader owned capacity on both sides of the ETS border. Therefore, understanding the interaction of these conflicting incentives is pertinent to our analysis. On a related note to our aforementioned point about the broader sustainable transition, future work could investigate the role of flexible producers in carbon-capped markets, e.g., in New York and Québec where the water allocation to the dominant hydro producer in the region could be regulated differently in order to prevent the manipulation of prices and adverse environmental consequences. A bi-level framework could be developed in which a regulator at the upper level can set not only the emission cap but also the water allocation in order to induce outcomes by industry at the lower level that are more aligned with the social optimum. Finally, in the spirit of Spiridonova (2016), it would be relevant to consider more firms with market power, which would constitute an equilibrium problem with equilibrium constraints.

\section{Acknowledgements}

Siddiqui has been supported by funding received from the Social Sciences and Humanities Research Council (SSHRC) of Canada under grant number 435-2017-0068. Višković is grateful for support from the UCL Centre for Doctoral Training in Financial Computing \& Analytics and HEC Montréal's Chair in Energy Sector Management. We have benefited from feedback received at the 2018 EURO Conference, the 2019 International Conference of the International Association for Energy Economics, and the 2020 Annual Conference of the Italian Association of Environmental and Resource Economists as well as seminars at the Research Institute of Industrial Economics (IFN Stockholm), the University of Economics, Prague (VŠE), and HEC Montréal. Comments from the handling editor and four anonymous referees have greatly improved the paper. All remaining errors are the authors' own. 


\section{References}

Bjørndal, E., M. Bjørndal, and H. Cai (2014). "Nodal Pricing in a Coupled Electricity Market.” 11th International Conference on the European Energy Market, 1-6.

Borenstein, S. (2000). "Understanding Competitive Pricing and Market Power in Wholesale Electricity Markets." The Electricity Journal, 13(6): 49-57.

Burtraw, D., D. Kahn, and K. Palmer (2006). " $\mathrm{CO}_{2}$ Allowance Allocation in the Regional Greenhouse Gas Initiative and the Effect on Electricity Investors.” The Electricity Journal, 19(2): 79-90.

Bushnell, J. B. and Y. Chen (2012). "Allocation and Leakage in Regional Cap-and-Trade Markets for $\mathrm{CO}_{2}$." Resource and Energy Economics, 34: 647-668.

Bushnell, J. B., E. T. Mansur, and C. Saravia (2008). "Vertical Arrangements, Market Structure, and Competition: An Analysis of Restructured U.S. Electricity Markets.” American Economic Review, 98(1): 237-266.

CEE Bankwatch Network (2017). Planned Coal Power Plants in the Western Balkans versus EU Pollution Standards. https://bankwatch.org/publication/ planned-coal-power-plants-in-the-western-balkans-versus-eu-pollution-standards

Chen, Y. and B. F. Hobbs (2005). "An Oligopolistic Power Market Model with Tradable $\mathrm{NO}_{x}$ Permits." IEEE Transactions on Power Systems, 20(1): 119-129.

Chen, Y., B. F. Hobbs, S. Leyffer, and T. S. Munson (2006). "Leader-Follower Equilibria for Electric Power and $\mathrm{NO}_{x}$ Allowances Markets." Computational Management Science, 3: 307-330.

Chen, Y., M. Tanaka, and A. S. Siddiqui (2018). "Market Power with Tradable Performance-Based $\mathrm{CO}_{2}$ Emission Standards in the Electricity Sector.” The Energy Journal, 39: 95-119.

Dietrich, K., U. Hennemeier, S. Hetzel, T. Jeske, F. Leuthold, I. Rumiantseva, H. Rummel, S. Sommer, C. Sternberg, and C. Vith (2005). "Nodal Pricing in the German Electricity Sector-A Welfare Economics Analysis, with Particular Reference to Implementing Offshore Wind Capacities." Working Paper WPEM-08, Chair of Energy Economics and Public Sector Management, Dresden University of Technology, Dresden, Germany. https://tu-dresden.de/die_tu_dresden/ fakultaeten/fakultaet_wirtschaftswissenschaften/bwl/ee2/dateien/ordner_publikationen/wp_ge_ 08_dietrich_hennemeier_hetzel_etal_nodal_pricing_germany.pdf

Dorn, W. S. (1960). "Duality in Quadratic Programming." Quarterly of Applied Mathematics, 18(2): 155-162.

Egerer, J., C. Gerbaulet, R. Ihlenburg, F. Kunz, B. Reinhard, C. von Hirschhausen, A. Weber, and J. Weibezahn (2014). "Electricity Sector Data for Policy-Relevant Modeling: Data Documentation and Applications to the German and European Electricity Markets." DIW, Berlin, Germany. http://www.diw.de/documents/publikationen/73/diw_ 01.c.440963.de/diw_datadoc_2014-072.pdf

European Commission (2018a). The EU Emissions Trading System. https://ec.europa.eu/clima/policies/ets_en

European Commission (2018b). Strategy for the Western Balkans. https://ec.europa.eu/commission/news/ strategy-western-balkans-2018-feb-06_en

ENTSO-E (2013). Yearly Statistics and Adequacy Retrospect. https://docstore.entsoe.eu/Documents/ Publications/Statistics/YSAR/141515_YSAR_2013_report.pdf

ENTSO-E (2016). Project 28 - Italy - Montenegro.https://docstore .entsoe. eu/Documents/TYNDP\%20documents/ TYNDP\%202016/projects/P0Q28.pdf

ENTSO-E (2018). Bidding Zone Configuration Technical Report 2018. https://docstore.entsoe.eu/Documents/ Events/2018/BZ_report/20181015_BZ_TR_FINAL.pdf

EU (2012). Gazzetta Ufficiale dell'Unione Europea.https ://eur-lex . europa. eu/legal-content/IT/TXT/PDF/?uri= 0]:L:2012:181: FULL\&from=IT

Eurostat (2014). Electricity and Heat Statistics. http://ec . europa . eu/eurostat/statistics-explained/index .php/ Electricity_and_heat_statistics

Fischer, C. and A. K. Fox (2012). "Comparing Policies to Combat Emissions Leakage: Border Carbon Adjustments versus Rebates.” Journal of Environmental Economics and Management, 64: 199-216.

Fortuny-Amat, J. and B. McCarl (1981). "A Representation and Economic Interpretation of a Two-Level Programming Problem." Journal of the Operational Research Society, 32(9): 783-792.

Fowlie, M. L. (2009). "Incomplete Environmental Regulation, Imperfect Competition, and Emissions Leakage.” American Economic Journal: Economic Policy, 1(2): 72-112.

Gabriel, S. A. and F. U. Leuthold (2010). "Solving Discretely-Constrained MPEC Problems with Applications in Electric Power Markets." Energy Economics, 32: 3-14.

Green, R. (2007). “Nodal Pricing of Electricity: How Much Does It Cost to Get It Wrong?” Journal of Regulatory Economics, 31(2): 125-149.

Copyright (C) 2018 by the IAEE. All rights reserved. 
Hahn, R. W. (1984). “Market Power and Transferable Property Rights.” Quarterly Journal of Economics, 99(4): 753-765.

Hobbs, B. F., C. B. Metzler, and J.-S. Pang (2000). "Strategic Gaming Analysis for Electric Power Systems: An MPEC Approach.” IEEE Transactions on Power Systems, 15(2): 638-645.

Hobbs, B. F. (2001). "Linear Complementarity Models of Nash-Cournot Competition in Bilateral and POOLCO Power Markets." IEEE Transactions on Power Systems, 16(2): 194-202.

Hogan, W. W. (1992). "Contract Networks for Electric Power Transmission.” Journal of Regulatory Economics, 4: 211-242. Huppmann, D. and J. Egerer (2015). "National-Strategic Investment in European Power Transmission Capacity.” European Journal of Operational Research, 247: 191-203.

Iovino, F. and N. Tsitsianis (2020). Changes in European Energy Markets: What the Evidence Tells Us. Emerald Publishing Limited.

Jensen, J. and T. N. Rasmussen (2000). "Allocation of $\mathrm{CO}_{2}$ Emissions Permits: A General Equilibrium Analysis of Policy Instruments," Journal of Environmental Economics and Management, 40: 111-136.

Kolstad, J. and F. Wolak (2003). "Using Environmental Emissions Permit Prices to Raise Electricity Prices: Evidence from the California Electricity Market.” Technical report, Center for the Study of Energy Markets, UC Berkeley.

Limpaitoon, T., Y. Chen, and S S. Oren (2011). "The Impact of Carbon Cap and Trade Regulation on Congested Electricity Market Equilibrium,” Journal of Regulatory Economics, 40: 237-260.

Lise, W., J. Sijm, and B. F. Hobbs (2010). "The Impact of the EU ETS on Prices, Profits and Emissions in the Power Sector: Simulation Results with the COMPETES EU20 Model," Environmental and Resource Economics, 47: 23-44.

Neuhoff, K., J. Barquin, M. G. Boots, A. Ehrenmann, B. F. Hobbs, F. A. M. Rijkers, and M. Vázquez (2005). "NetworkConstrained Cournot Models of Liberalized Electricity Markets: The Devil is in the Details," Energy Economics, 27: 495-525.

Reichenberg, L., A. S. Siddiqui, and S. Wogrin (2018). "Policy Implications of Downscaling the Time Dimension in Power System Planning Models to Represent Variability in Renewable Output." Energy, 159: 870-877.

Salop, S. C. and D. T. Scheffman (1983). "Raising Rivals' Costs.” American Economic Review, 73(2): 267-271.

Sartzetakis, E. S. (1997). "Raising Rivals' Costs Strategies via Emission Permits Markets." Review of Industrial Organization, 12: $751-765$.

Sauma, E. E. and S. S. Oren (2007). "Economic Criteria for Planning Transmission Investment in Restructured Electricity Markets." IEEE Transactions on Power Systems, 22(4): 1394-1405.

Schröder, A., F. Kunz, J. Meiss, R. Mandelevitch, and C. von Hirschhausen (2013), "Current and prospective costs of electricity generation until 2050," Technical report, DIW, Berlin, Germany.https://www.diw.de/documents/publikationen/ 73/diw_01.c.424566.de/diw_datadoc_2013-068.pdf

Schweppe, F. C., M. C. Caramanis, R. D. Tabors, and R. E. Bohn (1988). Spot Pricing of Electricity. Springer Science \& Business Media, New York, NY, USA.

Spiridonova, O. (2016). "Transmission Capacities and Competition in Western European Electricity Market.” Energy Policy, 96: $260-273$.

Tangerås, T. and J. Mauritzen (2018). "Real-Time Versus Day-Ahead Market Power in a Hydro-Based Electricity Market," Journal of Industrial Economics, 66(4): 904-941.

Terna (2013). Dati provvisori esercizio 2013. http://download. terna.it/terna/0000/0118/52.pdf

Wilson, R. (2002). "Architecture of Power Markets.” Econometrica, 70(4): 1299-1340.

Višković, V., Y. Chen, and A. S. Siddiqui (2017). "Implications of the EU Emissions Trading System for the South-East Europe Regional Electricity Market.” Energy Economics, 65: 251-261.

Weigt, H. (2006). "A Time-Variant Welfare Economic Analysis of a Nodal Pricing Mechanism in Germany." Electricity Markets Working Paper No. EM-11, Department of Business Management and Economics, Dresden University of Technology, Dresden, Germany.https://papers.ssrn.com/sol3/papers.cfm?abstract_id=1137403 